\title{
Reflexões acerca do Ensino de História nos Programas Curriculares de Formação de Professores de História em Angola entre 2001 e 2012
}

\section{Reflections on Teaching History in the Curricular Programs of Teachers Training in Angola between 2001 and 2012}

Rebeca Helena André*

\section{Resumo}

$\mathrm{O}$ artigo propõe-se abordar um conjunto de problemas sobre o currículo da formação de professores de História e sugere uma visão estratégica versando o ensino no âmbito da formação de professores. Apresentando um quadro de fatos relacionados com as componentes e conteúdos dos programas curriculares de formação de professores de História em Angola, procura analisar aspetos importantes como o ensino da História e a construção do currículo escolar e pessoal do professor de História no contexto de um país que experimenta apostar na formação de professores com vista ao desenvolvimento da educação e da sociedade. Expõe-se assim uma reflexão sistémica que integra questões metodológicas, políticas e culturais de relevo do currículo de História na formação do professor de História.

Palavras-chave: currículo; programa curricular; formação do professor; ensino de História e Cultura.

\section{Abstract}

The article attempts to discuss a number of issues related to the syllabus used in training history teachers in Angola while at same time proposes an innovative and comprehensive approach. The author meticulously provides an insight in the curricular programs employed in training History teachers in Angola which is a country that has been attempting to endorse teachers training programs that meet the global educational demands and development of its society. Thus, the article's systemic reflection unveils the methodological, political and cultural issues exercised in the training of history teachers.

Keywords: curriculum; curricular program; teachers training; teaching History and Culture.

\footnotetext{
* Doutora em História pela Faculdade de Letras da Universidade do Porto (FLUP), investigadora do Citcem/FLUP e do Ceaup. historia923@gmail.com
} 
Durante os primeiros anos que sucederam o marco da independência de Angola, vigorou no país o plano curricular herdado da educação colonial, lecionando-se sobretudo conteúdos relativos à História de Portugal no âmbito da disciplina de História. No passado colonial Angola integrava uma potência europeia, Portugal. Enquanto colónia e posteriormente província ultramarina, Angola era perspectivada como parte constituinte daquele país europeu, cumprindo o objetivo de demonstrar que Portugal era um país do Minho a Timor. Consequentemente, o ensino da História não retratava os fatos históricos, culturais e de vida destes povos, senão a dos povos europeus (portugueses) (André, 2010).

Em Angola, algumas das alterações efetuadas nos programas curriculares de História foram concretizadas para acompanhar as mudanças políticas, económicas e sociais que se operavam na conjuntura nacional. Em 1978, 3 anos após a proclamação da independência do país, foi aprovada a primeira reforma educativa. O ensino da História de Angola e de África foi então incluído no subsistema da formação de professores, tendo-se reduzido a carga de conteúdos da História Universal.

A Lei de Base no 13/01, de 31 dez. 2001, do sistema de educação que atualmente vigora em Angola, estabelece o subsistema da Formação de Professores do Pré-Escolar, Ensino Primário e $1^{\circ}$ e $2^{\circ}$ Ciclo Secundário. Esse subsistema define uma formação profissional de nível médio normal e superior, assente na perspetiva de que sejam proporcionadas ao professor competências polivalentes, que o capacitem para o ensino em Angola a nível pré-escolar, primário e secundário. De acordo com os objetivos estipulados para o subsistema de formação de professores, na sua base constam os princípios de "formar professores com o perfil necessário à materialização integral dos objetivos gerais da educação, formar professores com sólidos conhecimentos científico-técnicos e uma profunda consciência patriótica de modo a que assumam com responsabilidade a tarefa de educar as novas gerações e desenvolver ações de permanente atualização e aperfeiçoamento dos agentes de educação" (AngolaAssembleia Nacional, 2001, p.11).

O presente estudo resulta da análise dos dados obtidos no âmbito de uma tese de doutoramento (André, 2015), partindo dos objetivos definidos no subsistema de formação de professores e contemplando questões inerentes ao currículo no ensino da História e na formação de professores. No primeiro 
ponto expõem-se alguns princípios teóricos de currículo e suas componentes básicas nos programas curriculares de História. O segundo aborda o ensino da História no programa curricular das escolas do Magistério Primário e dos IMNE (Instituto Médio Normal de Educação), visando ainda reflexões sistémicas acerca do ensino de História no Instituto Superior das Ciências de Educação - Luanda. Por fim, o terceiro estabelece uma análise do perfil de formação dos estudantes do curso de formação de professores de História propondo-se uma reflexão sobre a qualidade do ensino da História e a construção do currículo de formação (escolar e pessoal) do estudante.

\section{Princípios teóricos do Currículo Em História}

A temática do currículo consubstancia-se como o grande desafio acerca do qual se discorre no presente artigo, apresentando-se como uma problemática a que a educação em Angola, no presente, procura responder. A História, enquanto depósito das memórias, dos hábitos e costumes dos homens e mulheres e do reconhecimento do passado, deve tornar-se um depósito promotor da modernização da educação histórica angolana. Dada a atribuição específica que a História cumpre no campo das ciências sociais, para além de abarcar os ensinamentos do passado o seu estudo ocupa-se identicamente do presente e, por sua vez, a boa conduta social do Homem depende da educação e de um percurso curricular. Este percurso principia nos primeiros anos de vida, e é na vida escolar e académica que o indivíduo despenderá mais tempo completando-se na vida profissional, sendo que o currículo pressupõe um trajeto, sob a forma de currículo escolar ou académico e currículo profissional, que é igual ao currículo de vida. O currículo escolar, quanto ao ensino dos conhecimentos, constitui o currículo base na vida de um indivíduo, e o professor encerra em si uma particularidade fundamental enquanto ferramenta para o culminar deste processo - o currículo de formação do indivíduo.

Nesse sentido, uma citação de Pinar et al. (apud Silva, 2000, p.43) recorre à etimologia da palavra curriculum para lhe dar um sentido concetual renovado; destaca que essa palavra, que originalmente significava "pista de corrida", deriva do verbo latino currere, correr. É assim, antes de tudo, um verbo, uma atividade ao invés de uma coisa, um substantivo. É como atividade que o currículo deve ser compreendido - uma atividade que não se limita à nossa vida 
escolar ou educacional, mas a todo o nosso percurso de vida. Estas tendências anglo-saxónicas quanto à perspetiva do currículo traduzem-se em mais "estudo, planificação, desenvolvimento e avaliação do processo institucional sistemático do ensino-aprendizagem" (Diago et al., 2008, p.22). Stenhouse (apud Leite, 2002, p.88) distingue a definição de currículo como "tentativa para comunicar as grandes finalidades de um propósito educativo, de forma que permaneça aberto à discussão crítica e possa ser mudado na prática”. Assim, verificamos que o currículo está ligado à existência de um sentido crítico que recebe reproduções de mudanças específicas e globais no indivíduo em face da realidade na qual está inserido. Essa perspetiva pode modificar o processo de adaptação dos valores sociais a que a Escola se propõe, tornando-a capaz de transformar a atitude da pessoa diante do contexto das relações sociais. A Escola, tendo conquistado um lugar cimeiro na sociedade moderna e acolhendo indivíduos de diferentes idades e origens sociais e culturais, deve ser a instituição em que o currículo, gerido com responsabilidade, preserva e espelha a realidade histórico-social e transforma as mentalidades.

A ação educacional nas sociedades permite a interpretação de fatos que provêm de vários contributos. Entre eles figura o ensino da História, que conduz à preservação da memória, de conhecimentos e valores das sociedades, proporcionando a solidariedade de uma convivência na diversidade. Esta ação não deve ser desenvolvida unicamente pela promoção de reflexões acerca das responsabilidades das escolas ante o papel dos programas curriculares da História das diferentes classes, mas também envolvendo todos na tarefa de educar em comunidade. No seu livro Uma teoria de educação, Joseph D. Novak (1981) apresenta contributos para a teoria da aprendizagem escolar. Na apresentação desse livro, Ralph Tyler considera a teoria de aprendizagem como guia central para o desenvolvimento do currículo e do programa de ensino. Todavia, a obtenção de conhecimentos sobre os contributos históricos de alguns autores (por exemplo, Tomás Tadeu da Silva, Joseph D. Novak) e sobre as teorias do currículo na educação ofereceu uma perspetiva sintética acerca da compreensão do currículo, desde as suas bases até ao desenvolvimento crítico da questão. Consequentemente, procurou-se analisar um corpo teórico que promovesse a explanação de questões sobre o currículo, deslocando-se para os problemas que os currículos escolares apresentavam, em Angola, no âmbito do ensino da História. 
A componente básica do currículo na formação de professores

Desde a proclamação da independência de Angola, no ano de 1975, o governo opta por um Sistema de Educação e Ensino caracterizado essencialmente por uma maior oportunidade de acesso à educação e à continuidade de estudos, pela gratuidade do ensino e do aperfeiçoamento permanente do pessoal docente. A responsabilidade por executar e incrementar a política educacional levou algumas vezes $(2000,2001,2004)$ à criação de uma entidade designada pelo Ministério da Educação e Cultura, na qual se basearam as mudanças de estratégia política do governo central angolano.

A organização curricular do ensino geral e da formação do professor do sistema educativo constitui-se determinante para o cumprimento das metas preconizadas pelo sistema educativo de um país. Tal afirmação é compreendida e reforçada quando se assume que "o currículo constitui o cerne do sistema escolar" (Ribeiro, 1990, p.36). Refira-se, em síntese, que a organização curricular se distingue a partir da identificação dos "componentes básicos de um currículo, tais como: finalidades e objectivos; matérias e conteúdos; estratégias e actividade; e a avaliação. Por outras palavras, um currículo contém o enunciado das finalidades e objectivos visados, propõe ou indica uma selecção e organização de conteúdos de ensino, implica ou sugere modelos, métodos e actividades de ensino-aprendizagem, em virtude dos objectivos que prossegue e de conteúdos que postula; inclui, por fim, um plano de avaliação dos resultados da aprendizagem" (ibidem, p.39). Note-se que a organização curricular é passível de ser caracterizada pela identificação das múltiplas componentes de um currículo.

Numa entrevista concedida a René Holenstein, Joseph Ki-Zerbo ressaltava uma passagem do livro Éduquer ou Périr: "A educação escolar surge como um quisto exógeno, um tumor maligno no corpo social. Efectivamente, o sistema educativo actual das sociedades africanas não está apenas em atraso em relação ao dos países industrializados; está sobretudo em contradição com as necessidades vitais, alimentares e elementares das referidas sociedades" (Ki-Zerbo, 2006, p.157). Nesse sentido, depreende-se que a educação, enquanto sistema e mais concretamente no que concerne à formação curricular, não deve estar dissociada das bases culturais de um povo, dado que deverá pressupor um estudo da realidade do tecido social educativo de uma região. Desejavelmente, 
tal estudo repercutir-se-á em currículos sustentados por esses mesmos elementos (por exemplo, a Língua, os hábitos e os costumes), que integrem, sobretudo, os aspetos positivos da tradição e os inscrevam no sistema educativo. Desse modo, cumprir-se-á o objetivo de modernizar a educação sem que ocorra uma desvinculação total dos valores educativos tradicionais locais (André, 2010, p.46). Analisando sob outro prisma, Ki-zerbo pretendia mostrar que procedendo-se à alteração dos programas se estariam a mudar os currículos, o que por sua vez geraria a mudança na escola que se pretende para o estilo da sociedade "africana" contemporânea (ibidem, p.46).

A organização curricular do sistema educativo em Angola é orientada por uma estrutura tradicional, cujo modelo se baseia em disciplinas (Zabalza, 2001, p.112-113) como sucede com a História, entre outras. Contudo, no subsistema do ensino primário (aquando das Reformas ocorridas em 1978 e 2001), nas quatro classes iniciais ( $1^{\mathrm{a}}$ à $4^{\mathrm{a}}$ ) esse modelo está associado ao modelo de situações e funções sociais integrando outras disciplinas. A estratégia de aplicação da reforma educativa (2001), baseado na disciplina de História estudada nas $5^{\mathrm{a}}$ e $6^{\mathrm{a}}$ classes, visa reduzir gradualmente os conteúdos relativos à História universal articulando-os com a História de Angola e de África, potenciando assim a formação integral da pessoa. Essa tendência da estratégia curricular que contempla as funções sociais pode ser integrada na disciplina de História, nomeadamente potenciando a compreensão da formação da cultura e identidade (cidadania), operacionalizando-a através dos planos de formação de todos os níveis de ensino e fundamentalmente no âmbito da formação de professores. O currículo escolar não serve ao propósito único de preparar os cidadãos para atingir o objetivo de concluir um bacharelado ou aceder à universidade, contemplando-se fundamentalmente a função social que desempenha, que "no período da escolarização obrigatória é essencial" (Muñoz et al., 2005, p.49). Não obstante, reconhece-se que "um currículo democrático deve ser comum, cooperativo, útil, inclusivo, prático, realizável, reflexivo, moral, planificado e coerente ... a identificação destes princípios nos parece muito adequada e por eles optamos, mas temos que fazer uma interpretação de cada um deles, mais aberta, actualizada e, sobretudo, relacionada com a nossa realidade educativa" (ibidem, p.46). Embora nesse âmbito pouco ou nada tenha sido identificado nos planos curriculares de História quanto à formação de professores, a função social do currículo preconiza o legado da "historiografia 
universal, que incentiva a ideia de que o objecto fundamental do estudo da História é o facto político" (Rama, 1974, p.158). Na perspetiva de Félix Rachealh (apud Rama, 1974, p.159), a história política "é a unidade mais alta e, dentro dela, fica incluída a história social e cultural". Este pode ser ainda um problema para os construtores de currículos uma vez que precisarão de ter claras as suas tendências para formular as suas estratégias de currículos e experimentar modelos com especificidades que correspondam à sociedade angolana.

Em Angola, a organização curricular do subsistema da formação de professores do $1^{\circ}$ ciclo do ensino secundário, a vigorar desde a reforma educativa de 2001, contempla "o perfil de saída do professor do $1^{\circ}$ ciclo do ensino secundário; as inovações em relação ao plano de estudos vigente; a análise da estrutura conceptual dos conteúdos e estratégias de sequenciação, entre outros. Uma análise sobre o ensino da História neste ciclo particulariza a sucessão periódica da evolução histórica a partir do estudo que abrangem: uma linha temporal desde a antiguidade até à resistência da ocupação colonial a atualidade, visam um período cronológico pautado por relações humanas entre os próprios africanos e os colonizadores (Angola-Med-Inide, 2009); revoluções americana, francesa e industrial inglesa (Angola-Med-Inide, s.d.-b); as grandes guerras, descolonização da Ásia e África, guerra fria e grandes problemas do mundo atual" (Angola-Med-Inide, s.d.-c).

Os conhecimentos relativos a todos os fatos históricos devem contribuir para uma educação curricular assente nos valores culturais e de identidade, de modo a que os estudantes sejam capacitados para discernir e reconhecer a importância de conceitos como a multiculturalidade, interculturalidade, angolanidade, tolerância e paz, entre outros que em diversos momentos da História de Angola, de África e do Mundo deverão ser cumpridos pelo Homem. Estas características, de que o currículo se deverá dotar, espoletam questões de (in)compatibilidade entre a identidade moderna e a realidade de um país. De acordo com Zabalza, o currículo "é o conjunto dos pressupostos de partida, das metas que se desejam alcançar e dos passos que dão para as alcançar; é o conjunto de conhecimentos, habilidades, atitudes, etc. que são considerados importantes para serem trabalhados na escola, ano após ano" (Zabalza, 2001, p.12). 


\section{O ENSINO DA HISTÓRIA NO PROGRAMA CURRICULAR}

\section{Nas escolas do Magistério Primário}

As escolas do magistério primário enquadram-se no ensino médio do subsistema da formação de professores, e o percurso que abrangem tem a duração de 4 anos. $\mathrm{O}$ ensino da disciplina de História é lecionado unicamente na décima ( $10^{\mathrm{a}}$ ) classe, ou seja, no primeiro ano de formação (Angola-MedInide, s.d.-a). O programa curricular do Magistério Primário evidenciou como objetivo fundamental a consolidação dos conhecimentos dos futuros professores do ensino primário por meio dos conteúdos de História lecionados nas classes anteriores, no que respeita à História de Angola e de África. Porém, atentando na disposição dos conteúdos e dos objetivos fixados no programa, são maioritariamente referenciados conteúdos de História da África, numa perspetiva vertical, enfatizando-se uma lacuna ao nível do estudo da História de Angola.

O exercício de uma atividade docente exemplar, no âmbito da disciplina de História, depende substancialmente de uma instrução e formação cuidada, adquirida ao longo do percurso académico. O conhecimento dos conteúdos de História pressupõe não apenas capacitar o professor primário ao nível da sua competência intelectual, mas também potenciar a sua conduta enquanto desejável cidadão exemplar. Do programa curricular de História constam múltiplos objetivos gerais da disciplina, entre os quais se destaca a intenção de proporcionar uma formação cívica, que visa preparar os futuros professores do ensino primário para um exercício consciente da cidadania, bem como o fomento do desenvolvimento de atitudes de respeito pelos valores tradicionais, pela vida e dignidade humana, pela unidade nacional, pela fraternidade e pela igualdade (Angola-Med-Inide, s.d.-a).

Atentando numa análise cuidada dos programas curriculares visados no âmbito da formação de professores para a formação da cidadania, os seus objectivos - particularizados na linha temporal que se desenha desde a antiguidade até à resistência da ocupação colonial, pautada por relações humanas entre os próprios africanos e os colonizadores (Angola-Med-Inide, 2009) dificilmente são alcançados com substância pois não obedecem à planificação desejada. No entanto, os conteúdos programáticos deveriam ser estabelecidos 
numa ordem transversal, não descurando os programas do subsistema do ensino geral ou as questões políticas culturais e identitárias. O quotidiano do ensino escolar angolano propõe-se à fomentação de iniciativas curriculares nos programas de ensino da história. Bruner (1999, p.42) considera que "o ritmo de mudança na sociedade em que vivemos força-nos a redefinir a maneira como havemos de educar uma nova geração". Por essa razão, o professor é responsável por tornar acessível aos alunos a aprendizagem dos conhecimentos históricos, nomeadamente pela programação de conteúdos e pelo exercício de metodologias combinadas. Para tal, torna-se crucial que o professor labore com um programa curricular que lhe possibilite desenhar a sua programação conforme os interesses do Estado, do programador e da sociedade. Entre inúmeras possíveis definições de programação, Zabalza (2001, p.17) define o conceito como "uma série de operações que os professores, em conjunto ou em grupos de dimensões mais reduzidas ... levam a efeito para organizar, a nível concreto, a actividade didáctica e dessa forma, porem em prática aquelas experiências de aprendizagem que constituirão o currículo efectivamente seguido pelos alunos". Também no seu entendimento, por meio da programação "territorializam-se os pressupostos gerais do Programa. Reinterpretam-se, a partir dos parâmetros de uma situação e de condições específicas, as previsões e compromissos ... do Programa" (ibidem, p.18). O conhecimento dos fatos da História de África imprime nos estudantes uma consciência do modo de vida dos seus antepassados que deverá ser trabalhada no sentido de que cada aluno-professor seja capaz de refletir e, consequentemente, contribuir para uma educação assente nos primordiais valores humanos e culturais.

\section{Nos Institutos Médios Normais de Educação}

A construção de programas da formação de professores do $1^{\circ}$ ciclo do ensino secundário é estruturada em 4 anos. Na 10a classe, o programa curricular de História da Formação de Professores define, quanto aos objetivos gerais da História, entre outros, "desenvolver consciência crítica em relação aos valores e padrões culturais nacionais; assegurar uma formação cívica visando a preparação para o exercício consciente da cidadania; e contribuir para o desenvolvimento de atitudes de respeito pelos valores tradicionais, pela vida e dignidade humana, pela unidade nacional, fraternidade e igualdade" 
(Angola-Med-Inide, s.d.). No que concerne aos objetivos gerais da História, na mesma classe, eles consistem, entre outros, em "aprofundar e consolidar os conhecimentos adquiridos nas classes anteriores sobre a História de Angola e África; conhecer os principais problemas da África de Hoje; conhecer a necessidade da Unidade africana na sua luta pelo desenvolvimento; avaliar a globalização como um fenómeno global do qual ninguém pode fugir, mas cujas consequências negativas podem ser minimizadas" (ibidem).

Quanto ao programa de História dos Institutos de Formação de professores relativo ao $1^{\circ}$ ciclo do ensino secundário, estruturados nos IMNEs (Instituto Médio Normal de Educação), a quantidade de conteúdos e a carga horária em que são lecionados são os mesmos ao nível das especialidades de Português/EMC, Inglês/EMC, e Francês/EMC e História/Geografia. Esse programa é utilizado na formação geral das referidas especialidades nos cursos dos IMNEs. Entre a $11^{\circ}$ e a $13^{\text {a }}$ classes, a formação deixa de ser geral e passa a ser profissional. Nos cursos de línguas, o programa curricular engloba disciplinas específicas, profissionais e ainda facultativas para a mesma especialidade. No que respeita à especialidade de História/Geografia, refira-se que a disciplina de História é lecionada ao longo de todo o processo formativo. Concretamente na $11^{\text {a }}$ classe, o programa de História da Especialidade História-Geografia foi construído respeitando os conteúdos e horas programáticas explicitados, ressaltando-se porém que os sete temas abordados aludem à História Universal.

Nas palavras do seu autor, o programa da $11^{\text {a }}$ classe de formação de professores "abarca aspetos de História Universal, da Expansão Europeia à ocupação efetiva de África pelas potências coloniais” (Angola-Med-Inide, s.d.-b, p.2), aludindo-se ainda à inclusão do quadro cronológico da História Universal concernindo aos acontecimentos de âmbito internacional no contexto da abordagem da História da Europa e da História de África. O processo de ensino e aprendizagem desses conteúdos concorre para que os alunos adquiriram conhecimento acerca das complexas conexões entre a política e a cultura. Cumprido tal objetivo estaremos em consonância com as orientações curriculares que Apple (1999, p.195) visiona para o conhecimento oficial, em dois modos: enquanto "resultado mercadorizado de um processo histórico e político complexo, pelo qual são disponibilizadas formas particulares de conhecimento e modos de conhecer ... a cultura legítima é vista como um objeto; a 
cultura é vista como vivida. Um currículo vivido, um currículo em uso, que incorpora múltiplas e contraditórias relações de poder é produzido nas interações corporais e linguísticas entre textos, alunos e professores em instituições educativas, e entre estas instituições e outras locais".

Nos currículos e seus programas devem ser identicamente privilegiadas estratégias que conduzam à produção de melhores resultados académicos mas, primordialmente, à interiorização de valores pessoais e de cidadania que concorram para a estabilidade social. No passado, nomeadamente nas décadas de 1960, 1970 e 1980, em Angola os professores consubstanciavam-se individualidades e modelos significativos para os pais, para os encarregados de educação e para a sociedade em geral. Alguns autores consideram que, atualmente, a imagem social do professor encontra-se em declínio, sucedendo uma perda de prestígio associada às alterações do papel tradicional dos professores no meio local (Jesus, 2000, p.28). Considera-se, portanto, premente que os professores se destaquem, cooperando com os construtores de currículos no âmbito de uma adequada delineação do processo formativo, nomeadamente elaborando currículos que aludam aos mais diversos factos históricos da política e cultura, atentando no universo das sociedades da atualidade e particularmente na idiossincrasia de Angola.

No que concerne à $12^{\text {a }}$ classe, os objetivos gerais da disciplina de História propõem que se transmita o conhecimento das principais características do imperialismo, "a importância histórica da Revolução Socialista de Outubro de 1917; as principais características do desenvolvimento socioeconómico e político do Mundo entre as duas guerras; o processo histórico da descolonização da Ásia e da África e os movimentos independentistas; analisar de forma crítica os grandes problemas da actualidade e em particular os do continente africano; conhecimentos que contribuam para análise e crítica de documentos históricos e desenvolver capacidades e atitudes que contribuam para o estudo científico da ciência histórica" (Angola-Med-Inide, s.d.-b). Torna-se então perceptível, à semelhança do que sucede com outros programas curriculares, a ausência de temas que desejavelmente deveriam configurar um conjunto ordenado de questões sociais inerentes ao ambiente vivenciado pelo aluno.

Em sua essência, alguns dos subtemas supraenumerados, que integram o programa curricular da $12^{\text {a }}$ classe - tal como outros, repetidos na $13^{\text {a }}$ classe expõem uma abordagem analítica dos diferentes temas transversais que 
compõem o ensino da História. O objetivo específico determinado para o subtema no programa da $13^{a}$ classe, "os conflitos regionais", consiste em "realizar ações para assegurar a estabilidade do planeta e do continente africano”. A título de exemplo, refira-se que a operacionalização desse objetivo poderá proporcionar a transmissão de conhecimentos vocacionados para a educação cultural e identitária, nomeadamente visando o conceito de respeito entre os diferentes povos. Esta será uma entre as múltiplas questões a serem consideradas enquanto problemática das origens dos conflitos regionais, abarcando países multiétnicos e multilíngues, como Angola, e/ou países vizinhos cujos povos partilham da mesma identidade étnica.

Note-se que a História de Angola não consta, como disciplina, no programa curricular de História dos IMNEs, tal como não se verifica nele uma integração de conteúdos. A título explicativo, equaciona-se que a referida lacuna esteja associada aos fatos de construção de uma historiografia da História de Angola. No subsistema da formação de professores, os conhecimentos específicos da disciplina na área da cultura se distingue da história política e da história económica. Na verdade, conforme refere Rama (1974, p.164), “o pormenor histórico-cultural tem o seu lugar adequado no campo dos usos e costumes, no domínio do folclore, das antiguidades, e degenera facilmente em curiosidades". A complementaridade desse pormenor adquire mais expressão na integração das realidades sociais (culturais) vivenciadas tanto nas sociedades do passado como no presente histórico, sendo a transmissão desses mesmos conhecimentos contemplada nos currículos de ensino.

\section{Reflexões Sistémicas sobre o Ensino de História no Instituto Superior das Ciências de Educação (ISCED) - Luanda}

Um dos procedimentos fundamentais para a existência do ensino superior orientado para a formação de professores consiste em adotar a agregação pedagógica para os professores dos diferentes subsistemas e níveis de ensino. No ISCED formavam-se professores de História que lecionavam no ensino geral e nos Institutos Médios. Atualmente, o ensino da História no subsistema da formação do professor aborda uma inclusão de conteúdos de História com cariz político e não de conteúdos culturais. Entre as 236 horas semanais que compõem a carga horária do plano curricular do curso de formação de 
professores de História, 32 horas foram designadas para os conteúdos de História Universal, 24 horas para a História de África, 20 horas para Didática e 14 horas para o ensino da História de Angola.

No Instituto Superior das Ciências da Educação de Luanda, a título de exemplo, atente-se no fato de a História Universal ser estudada em todos os anos académicos da formação de professor. A História de África era estudada durante os 3 primeiros anos e a História de Angola unicamente no $2^{\circ}$ e $3^{\circ}$ anos. Não menos relevantes são as cifras temporais relativas aos diferentes campos do ensino da História. Marc Bloch e Lucien Febvre tentam contribuir com "um novo tipo de história que tomava como objeto os seres humanos, os ritmos da vida..." (Cannadine, 2006, p.113). O ensino de história vive em paralela competição com a sociedade do conhecimento, tema sobre o qual Luís Osandón Millavil (2007, p.263) discorre procurando explicitar novas relações entre currículo e historiografia. Nesse sentido, o ensino da História serve-se da historiografia para a tornar dinâmica, visando realidades sociais cujas metodologias se centram nos fundamentos da história do passado e do presente. Sublinhe-se que as universidades são instituições produtoras do saber e conhecimento e, no caso do ISCED-Luanda esta instituição, quanto à área de História, deve colocar o enfoque da sua missão de ensino de História na sua vinculação à formação das pessoas (angolanas) e das suas vidas nas produções políticas, culturais e de identidade.

À semelhança do que se sugere nos programas de História dos níveis inferiores de ensino, no âmbito do ensino da História de Angola o plano de estudo do curso de História do ISCED está em fase de constituição, organização e apreciação dos estudos disponíveis relativos à historiografia angolana.

A orientação de estudos que incidam na historiografia angolana concorre para um melhor desempenho da atividade profissional do professor de História, auxiliando tanto ao nível da pesquisa de temas históricos como na transmissão de conhecimentos sobre eles. Destaque-se que algumas obras de referência historiográfica angolana assumem importância como suporte dos currículos de ensino de História nos vários níveis de ensino. Entre inúmeras considere-se a obra de José Rendinha (1962, p.9), que busca fazer-nos compreender que Angola é um território cuja população se apresenta multiétnica e multilinguística. No ano de 1991, a existência de múltiplas línguas nativas em Angola levou o Ministério da Educação a promover um debate numa 
Mesa-Redonda sobre Educação para Todos. Dessa tertúlia emergiram perspetivas como a revitalização desse instrumento de comunicação ao nível das escolas a fim de travar o desaparecimento das identidades culturais dos povos. Sublinhe-se que as diferentes origens da população angolana e das línguas nativas faladas constituem o símbolo da identidade deste povo e "são muito importantes para a conservação da multiplicidade cultural angolana” (André, 2010, p.40). Por meio da convivência histórica com a potência colonial portuguesa, a Língua Portuguesa constituiu-se na língua oficial de Angola - um traço de identidade dos povos de Angola, o vínculo da cultura social, da convivência dos diversos povos que habitam em Angola (André, 2010, p.39). Associados à Língua contam-se identicamente outros traços comuns de uso nalguns destes povos, representados pelos estilos europeus, como o nome pessoal, a alimentação e o vestuário que foi muito comum no passado colonial e fruto do mundo globalizado (Azevedo, 1963).

Em suma, pode-se afirmar que no subsistema da formação de professores a instrução e consolidação da angolanidade pode ser alcançável com recurso à elaboração de programas com finalidades, objetivos e conteúdos de História - visando a História de Angola e a integração da História da África e do Mundo - numa ação pautada por uma revisão sistemática, concetual e metodológica, das questões culturais e identitárias.

O livro Novos temas nas aulas de História (Pinsky et al., 2009, p.8) propõe um verdadeiro desafio sobre a transversalidade do ensino da História, indicador necessário de estudos para as realidades culturais das sociedades na actualidade. Ao longo de toda a obra está patente a abordagem que incentiva à construção de uma mais-valia para os investigadores, historiadores, professores e estudantes. Entre os diversos temas abordados, a cultura insere-se no quotidiano dos indivíduos e nas propostas didácticas que orientam a função do ensino-aprendizagem da História. A propósito do conceito de cultura e de como este se traduz em experiências escolares, Marco Napolitano (Pinsky et al., 2009, p.8) destaca os debates sobre cultura em Ciências Humanas e as propostas curriculares do sistema de ensino brasileiro. Enaltece a importância do tema "cultura" para os estudantes, em face de várias perspetivas e problemáticas para a definição do conceito e dimensão histórica, e destaca "o incentivo à cultura, em todos os seus matizes e definições, como um caminho importante, que deve estar paralelo à promoção da cidadania em qualquer 
projecto educacional e afirma que a própria experiência escolar faz parte da vida cultural de uma sociedade" (ibidem, p.74).

No caso de Angola, cuja população é multicultural e multilíngue, as questões curriculares com integração desses conhecimentos constitui-se fundamental para a formação de uma identidade nacional. Consequentemente, as experiências curricular e escolar dessas questões tornam-se desafio de aplicação metodológica em aulas de História. Ainda acerca do tema da cultura no currículo, o autor exprime o sentido de definição de cultura consoante com os parâmetros curriculares nacionais, e, de acordo com a sua análise, distinguir-se-á a tríade pela abordagem no âmbito das disciplinas de História, Antropologia e Filosofia. Contudo, o autor reconhece que na época atual "não importa o modo como o professor pretende dar a matéria ou quais recursos didácticos emprega - aula expositiva, leituras de textos, estudos do meio, audiovisuais, visita a museus, trabalho em grupo, ou outros. A proposta de novos temas de História, na sala de aula, é a de que todos os temas apresentados podem e devem ser incorporados como parte do olhar sobre a história no ensino e daí para novas e enriquecedoras visões de mundo" (Pinsky et al., 2009, p.9). Por sua vez, a incorporação desse estudo na disciplina de História dependerá do que for coordenado e planificado, bem como dos conhecimentos sobre as didáticas específicas. Maria Proença (1989, p.34) expõe que "a prática lectiva do professor de História deve ser integradora e global abrangendo as dimensões científicas, técnicas, humanistas e político-social de didáctica”. Em suma, a integração da cultura ou de outro tema nos programas curriculares de História concorre para um sistema transversal do ensino da história.

\section{ANÁLISE DO PERFIL DE FORMAÇÃO DOS ESTUDANTES DO CURSO DE PROFESSORES DE HISTÓRIA}

Em vigor desde o ano de 2010, o atual plano curricular do curso de História apresenta, de um modo geral, um evidente desequilíbrio no que concerne aos domínios abrangidos pelo estudo da História (por exemplo, História do Mundo, História de África e História de Angola). A vertente metodológica para a aplicação dos conhecimentos de História é complementada pela disciplina de Metodologia do Ensino da História. Esta disciplina, abrangida nesse 
curso, capacita o futuro professor com teorias didáticas que possibilitam o exercício da sua atividade docente, muito específica no campo da História.

Já exposta uma perspectiva panorâmica do ensino da História nos dois níveis do subsistema da formação de professores, urge questionar qual o perfil de formação que se pretende para os estudantes do curso de formação de professores de História.

O percurso curricular do programa de ensino, no que respeita aos conteúdos das disciplinas, permite estabelecer um perfil de formação desses estudantes, atentando no saber, saber fazer, saber ser e saber conviver. O estudante, futuro professor primário, encontra-se munido da sua própria memória da construção do seu currículo pessoal, desde as primeiras idades escolares até ao momento em que se encontra matriculado, enquanto estudante do secundário ou de outro nível de ensino. Essa memória deverá servir de representação e concomitantemente potenciar o desenvolvimento da sua atitude e outras qualidades, almejando-se o desempenho excelente de um professor do ensino primário. Entre outras competências, a capacidade de identificar em retrospetiva todo, ou quase todo, o seu passado enquanto criança e as curiosidades então vividas, no seu mundo infantil, poderá ser útil para compreensão das vivências dos alunos (crianças) que agora ensina. Nesse sentido, o seu posicionamento enquanto indivíduo permitirá conhecer o outro (o aluno desse nível) enquanto sujeito, simultaneamente conhecendo e dominando os diversos fatores inerentes à sua atividade (legal, institucional e organizacional), incluindo as mais diversas problemáticas relativas à sua área. $\mathrm{O}$ estudante deverá ser preparado, o mais possível, para desempenhar um papel fundamental na melhoria da educação e ser capaz de reconhecer a importância da sua aplicação no entendimento de como as pessoas aprendem o currículo, ensino e o ambiente da aprendizagem (Novak, 1981). Sublinhe-se ainda a premência de que domine “os conteúdos programáticos e os manuais escolares, as normas, as orientações metodológicas e outros instrumentos relativos à educação e ensino nas instituições escolares" (Angola-Med-Inide, 2009, p.10). Deverá o estudante ainda saber definir os objetivos das aprendizagens por meio das finalidades dos programas curriculares, considerando as condições da escola e do meio em que se insere. Mais, acrescente-se a necessidade imperiosa de que seja capaz de colaborar com os colegas da mesma classe, no sentido de que sejam proporcionadas 
trocas de experiências que se consubstanciem em contributos para o investimento fulcral na formação de cidadãos conscientes e participativos.

O professor deverá ser um profissional idóneo - moral, cívica e profissionalmente - e tal qualidade deverá ser enquadrada num perfil que apresente a sua competência. Note-se que, por definição, esse conceito, ao qual aludem Xavier Roegiers e Jean-Marie de Ketele (2004, p.89), não é linear ou consensual, deixando margem para confusão. Para Gerard e Roegiers (apud Roegiers; Ketele, 2004, p.45), competência é "como um conjunto integrado de capacidades que permite - de maneira espontânea - aprender uma situação e responder a ela mais ou menos pertinentemente". Por sua vez, Kitele (ibidem) define competência como um "conjunto ordenado de capacidades (atividades) que são exercidas sobre os conteúdos numa determinada categoria de situações para resolver problemas apresentadas por estas". No professor projectam-se essas características e competências, que lhe permitirão desempenhar com excelência a sua profissão enquanto educador. Nesse sentido, defende-se que uma formação de professores vá mais longe e permita desenvolver ações que fomentem nos professores uma reflexão sistemática acerca do seu próprio ensino, que promovam nos docentes a iniciativa de os próprios estudarem e investigarem estratégias do trabalho pedagógico de ensinar e identificarem o interesse em fazê-lo. Mais, que desenvolva uma nova atitude pedagógica, que desenvolva uma nova forma de estar em educação; que promova que os professores sejam capazes de um desenvolvimento profissional autónomo, incentivando que evidenciem atitudes de autoanálise atenta e permanente e onde não são ignoradas questões de ordem social (Martins; Correia, 2012, p.132).

$\mathrm{Na}$ disciplina curricular, a didática exerce o importante fundamento metodológico para o aperfeiçoamento da qualidade de ensino. O dicionário de pedagogia de Louis Arénilla refere que "a didáctica de uma disciplina integra, efectivamente, capacidades supostas transversais e homogéneas, como a atenção e a memória; o que era encarado como aptidões quase independentes do esforço específico de uma aprendizagem faz parte desta aprendizagem" (Arénilla et al., 2001, p.147). Para o professor atingir resultados no seu trabalho, com o currículo, necessita de elevar a didática às metodologias aplicáveis e eficazes e escolher a melhor via para uma melhor aprendizagem e ensino. Só nesta perspectiva o profissional atua como um facilitador, desempenhando a 
função de harmonizar os conhecimentos dos alunos - adquiridos na escola ou fora dela.

O ensino da História dirigido à Educação Histórica assume significância quando as disciplinas curriculares que a compõem são combinadas entre os vários campos de aprendizagem da História para a formação de professores. No que concerne à aprendizagem educativa da História, uma apreciação vertical permite verificar que o plano evidencia lacunas ao nível da variante de estudo da História social, nomeadamente quanto ao desejável propósito de que os estudantes assumam a tarefa de professores e cidadãos educadores da sociedade. De acordo com o nível de graduação o docente deve consolidar as metodologias e técnicas para trabalhar com perspicácia os programas curriculares a partir da exploração do currículo da classe e da disciplina que leciona. O seu perfil de formação deve determinar-se pelas experiências metodológicas do ensino de história, integrado e sistemático, refletidas no quotidiano da nação angolana e concebidas ao longo da sua formação.

No final da sua formação o professor deverá ser capaz de interpretar um currículo de formação da classe, do nível ou da disciplina. Se o professor manifesta ser insuficiente a sua capacidade para interpretar os estudos dos fenómenos políticos e culturais (sociais), isso afeta o processo de ensino-aprendizagem da História. Caso tal suceda, os objectivos definidos na organização dos programas curriculares da disciplina de História dificilmente poderão ser concebidos e praticados conforme idealizado, com o propósito de que o professor faça uso dos procedimentos, métodos e meios compatíveis ao alcance dos objetivos da aula e do desenvolvimento das capacidades dos alunos. Nessa linha de pensamento, o perfil de formação do estudante da formação do professor de História deve almejar um indivíduo profissionalmente professor-investigador ${ }^{1}$ e historiador-pedagogo ${ }^{2}$ - duplas vertentes de formação do professor de História integradas nos valores da aprendizagem das Ciências Sociais.

\section{CONSIDERAÇÕES FINAIS}

A visão estratégica de ensino na formação de professores assume-se basilar para o desenvolvimento de um sistema educativo que prime pela qualidade. Apple, acerca desta mesma questão, considera que "o ensino formal, em geral, 
é organizado e controlado pelo governo (o 'Estado'). Isto significa que para além de a educação ser um ... lugar de emprego renumerado, trata-se de uma questão política saber que metas usa atingir o sistema educativo e como é que essas metas serão avaliadas, quem tem o poder sobre ele...” (Apple, 1999, p.21). A prioridade dos diversos problemas que afetam a educação das sociedades é visada no âmbito das ciências sociais e humanas. Consequentemente, o investimento numa boa gestão da formação de currículos dirigidos a alunos/estudantes de vários níveis de ensino concorre para a qualidade do processo de ensino-aprendizagem, tornando evidente o modo como as aprendizagens dos currículos de formação de História nos subsistemas da formação de professor, no ensino médio e no ensino superior, podem ajudar a desenvolver a educação e a sociedade.

Nas escolas do Magistério primário, a disciplina de História é apresentada de forma fragmentada quanto aos campos da História, embora numa dinâmica de inter-relação com outras disciplinas tendentes a conservar os interesses políticos e sociais e nacionais direcionados para os cidadãos angolanos. A construção da memória responsável pela representação histórica nacional e pela identidade nacional procuram referência de poder nos programas curriculares da formação de professores primários e dos Institutos Médios Normais de Educação - IMNEs (André, 2015).

Enquanto disciplina escolar, a História de Angola pode ser percebida como pouco sólida, considerando-se a diminuta carga horária em que é leccionada - embora seja contemplada nos diversos anos que compõem o curso. Também a qualidade dos conteúdos teóricos, a frequência do estudo da disciplina e a sua transversalidade são parcamente constatadas nos currículos e programas curriculares. Tais factos poderão repercutir no (in)sucesso da aprendizagem desses conteúdos, dependendo das estratégias montadas a partir da formação (inicial/contínua) dos professores. Ao nível do ensino superior, dada a amplitude dos conteúdos que abrange, o ensino da História de Angola se beneficiaria de uma segmentação de diversas temáticas contemplando-se nomeadamente a História Local, a História de Heróis, a História Cultural e a História da Educação, entre outras. Semelhante procedimento, desenvolvido no currículo da formação de professores, pode enriquecer e fortalecer a competência do novo professor. 
Urge compreender que, no que respeita à promoção dos conhecimentos sobre a angolanidade nos estudantes dos cursos de formação de professores, a integração da História de Angola nesses mesmos programas curriculares pode assegurar a transferência desse conhecimento para a formação das novas gerações. Assim como defende Dray, "a História continua a ser (como é justo e necessário que seja) um elemento essencial da cultura e educação públicas e da vida nacional" (apud Cannadine, 2006, p.8), pelo que o seu ensino tem como finalidade a aquisição do conhecimento. Esse conhecimento deverá, fundamentalmente, servir à preparação do indivíduo para a sua afirmação na sociedade e enquanto facilitador para a compreensão dos diferentes fenómenos sociais, culturais e económicos, entre outros.

É crucial que se proceda a uma abordagem do estudo sistémico do ensino da História no subsistema do ensino geral e no subsistema da formação de professores, assim como no subsistema da formação de professores em todos os níveis. A evolução metodológica da investigação científica e os princípios teóricos e práticos da pedagogia no ensino da História podem constituir-se no desafio da educação histórica escolar na formação de professores dessa disciplina. Para uma melhor gestão do ensino da História nos programas curriculares concernentes aos 4 anos de formação de professores (médio e superior), o currículo deve ser revisitado periodicamente, aperfeiçoado numa dinâmica que se pretende de continuidade e evolutiva, com o objetivo de, consequentemente, ser promovida a essência dos conhecimentos históricos.

\section{REFERENCIAS}

ANDRÉ, Rebeca Helena. O ensino da História em Angola: balanço (1975/2009) e prospectiva. Dissertação (Mestrado em História e Educação) - Faculdade de Letras, Universidade do Porto. Porto, 2010.

O ensino da História em Angola entre 1960-2012: evolução, formação de professores e cooperação internacional. Tese (Doutorado em Letras) - Faculdade de Letras, Universidade do Porto. Porto, 2015.

ANGOLA. Assembleia Nacional. Lei de Bases n¹3/2001, de 31 de Dezembro de 2001, do Sistema de Educação (LBSEA). Luanda, 2001.

ANGOLA-MED-INIDE. Programa de História, Formação de Professores do Ensino Primário $10^{a}$ classe. Luanda, 2009. 
ANGOLA-MED-INIDE. Currículo de Formação de Professores do Pré-Escolar e do Ensino Primário Reforma Curricular. Luanda, 2009a.

ANGOLA-MED-INIDE. Currículo da Formação de Professores do $1^{\circ}$ Ciclo do Ensino Secundário (Melhorado). 2.ed. Luanda, 2010.

ANGOLA-MED-INIDE. Programa de História Formação de Professores do $1^{\circ}$ Ciclo do Ensino Secundário $10^{a}$ Classe-IMN Formação Geral. Luanda, s.d.

ANGOLA-MED-INIDE. Programa de História Formação de Professores do $1^{\circ}$ Ciclo do Ensino Secundário $10^{a}$ Classe-IMN Formação Profissional. Luanda. s.d.-a.

ANGOLA-MED-INIDE. Programa de História Formação de Professores do $1^{\circ}$ Ciclo do Ensino Secundário $11^{a}$ Classe-IMN Formação Profissional. Luanda, s.d.-b.

ANGOLA-MED-INIDE. Programa de História Formação de Professores do $1^{\circ}$ Ciclo do Ensino Secundário $12^{a}$ Classe-IMN Formação Profissional. Luanda, s.d.-c.

ANGOLA-MED-INIDE. Programa de História Formação de Professores do $2^{\circ}$ Ciclo do Ensino Secundário 13a Classe-IMN Formação Profissional. Luanda, s.d.-d.

APPLE, Michael W. Poder, significado e identidade: ensaios de estudos educacionais críticos. Porto: Porto Ed., 1999.

ARÉNILLA, Louis; GOSSOT, Bernard; ROLLAND, Marie-Claire; ROUSSEL, Marie-Pierre. Dicionário de Pedagogia. Trad. Maria Teresa Serpa. Lisboa: Instituto Piaget, 2001.

BRUNER, Jerome S. Para uma Teoria da Educação. Lisboa: Relógio D’Água, 1999.

CANNADINE, David. Que é a História Hoje? Trad. Rui Pires Cabral. Lisboa: Gradiva, 2006.

DIAGO, Jesús Cabrerizo; ROLDÁN, Ma Julio Rubio; ARREDONDO, Santiago Castillo. Programación por competencias: formación e práctica. Madrid: Pearson Educación, 2008.

JESUS, Saul Neves de. Motivação e formação de professores. Coimbra: Quarteto, 2000.

KI-ZERBO, Joseph. Para Quando África? Entrevista com René Holenstein. Trad. Carlos Aboim de Brito. Luanda: Caxinde, 2006.

LEITE, Carlinda Maria Faustino. O currículo e o multiculturalismo no Sistema Educativo Português. Coimbra: Fundação Calouste Gulbenkian; Fundação para a Ciência e a Tecnologia, 2002.

MARTINS, Felisbela; CORREIA, Luis. A formação de professores de História e Geografia na Faculdade de Letras da Universidade do Porto: o percurso à luz do processo de Bolonha (2008-2012). Revista de Geografia e Ordenamento do Território, Centro de Estudos de Geografia e Ordenamento do Território, n.1 (Junho), 2012.

MILLAVIL, Luís Osandón. O ensino da história na sociedade do conhecimento: no- 
vas relações entre currículo e históriografia. In: CARRETERO et al. Ensino da História e Memória Coletiva. Trad. Valério Campos. Porto Alegre: Artmed, 2007.

MUÑOZ, Juan Manuel Escudero; PALLÁS, Amador Guarro; CERÓN, Ginés Martínez; SALA, Xavier Riu. Sistema Educativo e Democracia. Barcelona: Octaedro, 2005.

NOVAK, Joseph D. Uma teoria de educação. Trad. Marco Antônio Moreira. São Paulo: Pioneira, 1981.

PINSKY, Carla Bassanezi; CAROLA, Carlos Renato; RAMOS, Fábio Pestana; SILVA, Kalina Vanderlei; MONDAINI, Marco; MARTINS, Marcos; NAPOLITANO, Marcos; MORAIS, Marcus Vinícius de; DIWAN, Pietra; FIGUEIRÔA, Sílvia. Novos temas nas aulas de História. São Paulo: Contexto, 2009.

PROENÇA, Maria Cândida. Didáctica da História. 2v. Lisboa: Universidade Aberta, 1989.

RAMA, Carlos M. Teoria da História: introdução aos estudos históricos. Trad. Albina Maia. (3.ed., 1980). Coimbra: Almedina, 1974.

RENDINHA, José. Distribuição Étnica de Angola. Luanda: Centro de Informação e Turismo de Angola, 1962.

RIBEIRO, António C. Desenvolvimento curricular. Lisboa: Texto Ed., 1990.

ROEGIERS, Xavier; KETELE, Jean-Marie de. Uma pedagogia da integração: competências e aquisições no ensino. Trad. Carolina Hueng. 2.ed. Porto Alegre: Artmed, 2004.

SILVA, Tomaz Tadeu. Teorias do currículo uma introdução crítica. Porto: Porto Ed., 2000.

ZABALZA, M. Planificação e desenvolvimento curricular na escola. Porto: Asa, 2001.

\section{NOTAS}

${ }^{1}$ É professor de História mas também investigador na sua ação de ensinar ou pela transferência dos conhecimentos.

${ }^{2}$ É um expert em História e pedagogia, ou seja, possui capacidades para aplicar determinados conhecimentos históricos e didáticos num processo de ensino-aprendizagem.

Artigo recebido em 22 de abril de 2015. Aprovado em 23 de julho de 2015. 